\title{
Vitamin D Status and Cardiovascular Health: A 2009 Update
}

\author{
Erin D. Michos ${ }^{*}, 1$ Jared P. Reis ${ }^{2}$ and Michal L. Melamed ${ }^{3}$ \\ ${ }^{I}$ Division of Cardiology, Johns Hopkins University School of Medicine, Baltimore, Maryland, USA \\ ${ }^{2}$ Division of Cardiovascular Sciences, National Heart, Lung, and Blood Institute, Bethesda, Maryland, USA \\ ${ }^{3}$ Departments of Medicine and Epidemiology and Population Health, Albert Einstein College of Medicine, Bronx, New \\ York, USA
}

\begin{abstract}
Vitamin D has long been known to be vital to bone health. More recently, vitamin D has been shown to play a role in the risk of malignancy, infection, autoimmune disease, renal disease, and cardiovascular disease (CVD) including its associated risk factors of diabetes and hypertension. Within the umbrella of cardiovascular disorders, low vitamin D levels have been specifically linked to increased risk of congestive heart failure, left ventricular hypertrophy, peripheral arterial disease, subclinical vascular disease, myocardial infarction, stroke, and mortality - associations that remain even after traditional risk factors and lifestyle factors are taken into account. However, a direct causal relationship between 25(OH)D deficiency and the risk of CVD has not been completely established.
\end{abstract}

A thorough review of the scientific evidence linking vitamin D deficiency with CVD as well as an explanation of the potential biologic mechanisms that may support these associations will be the focus of this review.

Keywords: Vitamin D, cardiovascular disease risk, review.

\section{INTRODUCTION}

Vitamin D has long been known to be vital to bone health [1]. More recently, vitamin D has been shown to play a role in the risk of malignancy [2], infection [3], autoimmune disease [4], renal disease [5], and cardiovascular disease (CVD) including its associated risk factors of diabetes and hypertension [6]. Within the umbrella of cardiovascular disorders, low vitamin D levels have been specifically linked to increased risk of congestive heart failure, left ventricular hypertrophy, peripheral arterial disease, subclinical vascular disease, myocardial infarction, stroke, and mortality - associations that remain even after traditional risk factors and lifestyle factors are taken into account [7].

Serum 25-hydroxyvitamin D [25(OH)D] levels vary with geography, seasonality, latitude, and altitude, presumably as a result of differences in exposure to sunlight. Interestingly, the risk of CVD is noted to be highest in areas of increased geographic latitude and during winter months, which parallels trends in low 25(OH)D levels [6]. Furthermore, survival is improved if cancer diagnosis occurs during the summer months when vitamin D levels are highest [8]. However, a direct causal relationship between 25(OH)D deficiency and the risk of CVD or cancer has not been completely established.

A thorough review of the scientific evidence linking vitamin D deficiency with CVD as well as an explanation of

*Address correspondence to this author at the Division of Cardiology, Johns Hopkins University School of Medicine, Carnegie 568, 600 N. Wolfe Street, Baltimore, MD 21287, USA; Tel: 410-502-6813; Fax: 410-502-0231; E-mail: edonnell@jhmi.edu the potential biologic mechanisms that may support these associations will be the focus of this review.

\section{SOURCES OF VITAMIN D}

The major source of vitamin $\mathrm{D}$ is endogenous production via the action of the sun's ultraviolet b (UVB) light on 7dehydrocholesterol precursors in the skin, converting them to vitamin D3 (cholecalciferol) [9]. Exogenous D3 can also be obtained from the diet from oily fish, fortified foods, or supplements. Vitamin D can also be found in the form of D2 (ergocalciferol) which is produced in plants after UVB radiation of ergosterol, and can also be consumed in the diet as a supplement or from fortified foods. Few foods naturally contain vitamin D or are actually fortified with vitamin D. However, even fortified foods contain relatively small amounts of vitamin D. Consider that $8 \mathrm{oz}$ of fortified milk usually only contains about $100 \mathrm{IU}$ of vitamin $\mathrm{D}$, and many experts believe that generally at least 800-1000 IU/day of vitamin D are needed to maintain healthy vitamin $\mathrm{D}$ levels in the absence of adequate sunlight exposure $[9,10]$.

Vitamin D undergoes 25-hydroxylation in the liver, to form $25(\mathrm{OH}) \mathrm{D}$, the primary circulating form of vitamin $\mathrm{D}$ and the metabolite that best reflects stores of vitamin D (i.e. sufficiency or deficiency states). The active metabolite, 1,25(OH)2D, (also called calcitriol), is formed after $1 \alpha$ hydroxylation in the kidneys. 25-OH Vitamin D 1 hydroxylase is known to be the rate-limiting enzyme in vitamin D biosynthesis. 1,25(OH)2D is responsible for all cellular processes involving vitamin $\mathrm{D}$. Although the main source of $1,25(\mathrm{OH}) 2 \mathrm{D}$ in the circulation is from renal $1 \alpha$ hydroxylation, it has been recently appreciated that many other tissues, including breast, colon and vascular smooth 
muscle cells also express $1 \alpha$-hydroxylase, and are therefore capable of local $1,25(\mathrm{OH}) 2 \mathrm{D}$ production [11]. In these tissues, the locally formed $1,25(\mathrm{OH})_{2} \mathrm{D}$ serves as a celldifferentiating factor. Extra-renal production of 1,25(OH)2D is thought to have a paracrine/autocrine function including an important role in innate (macrophage) immunity [11]. Levels of $1,25(\mathrm{OH}) 2 \mathrm{D}$ do not correlate well with $25(\mathrm{OH}) \mathrm{D}$ levels, and given tight regulation, $1,25(\mathrm{OH}) 2 \mathrm{D}$ levels may remain in the normal range even in the face of frank $25(\mathrm{OH}) \mathrm{D}$ deficiency.

\section{OPTIMAL VITAMIN D LEVELS AND RISK FAC- TORS FOR DEFICIENCY}

The optimal level of $25(\mathrm{OH}) \mathrm{D}$ has been suggested to be $\geq 30 \mathrm{ng} / \mathrm{ml}$ (75 nmol/L) [12], a level associated with maximal suppression of intact parathyroid hormone (iPTH) and reduced fracture rates. Most agree that $25(\mathrm{OH}) \mathrm{D}$ levels $<20$ $\mathrm{ng} / \mathrm{ml}$ are considered deficient [9]. Using $28 \mathrm{ng} / \mathrm{ml}$ as a cutoff, it is estimated that approximately $41 \%$ of men and $53 \%$ of women in the United States have insufficient levels of $25(\mathrm{OH}) \mathrm{D}$ based upon data from the nationally representative Third National Health and Nutrition Examination Survey (NHANES-III) conducted between 1988 and 1994 [13]. More recent data from NHANES has suggested that the prevalence of vitamin D deficiency may be increasing in the United States, especially among those who are more likely to be vitamin $D$ deficient $[14,15]$. Although vitamin D assay drifts do account for part of the changes in serum $25(\mathrm{OH}) \mathrm{D}$ levels between the NHANES surveys [16], changes in body mass index (BMI), milk intake, and use of sunscreen/sun protection appear to contribute to a real decline in vitamin D status among an adult subgroup [15].

Vitamin D deficiency is very common throughout the world. Individuals living at higher latitudes are particularly at risk; for those living above 35 degrees latitude, little or no vitamin D can be produced from November to February [9]. But even in parts of the world that receive adequate yearlong sun exposure, vitamin D deficiency may be common because of the covered manner of dress or use of sunscreen [10]. Melanin skin pigmentation absorbs UVB light reducing vitamin D synthesis, and thus race/ethnic groups with darker skin coloring living in the Northern hemisphere may be at particular risk for vitamin D deficiency. It is estimated that $80 \%$ of African-Americans living in the United States have insufficient levels of vitamin D [17]. Women in the United States also have lower 25(OH)D levels compared to men [14].

Aging is associated with vitamin D deficiency because of decreased concentrations of vitamin D precursors (7dehydrocholesterol) in the skin. Obesity is a strong risk factor for vitamin $\mathrm{D}$ deficiency because fat cells sequester vitamin D (as a steroid vitamin, it is fat-soluble), making stores less available to become biologically activated. Lower vitamin D levels among obese and older individuals may also stem from reduced sunlight exposure as a result of reduced outdoor activity. Serum vitamin D levels have been linked to frequency of out-door leisure-time physical activity [18].

It should be noted that excess sunlight cannot cause vitamin D toxicity because UVB rays destroy excess previtamin D stores in the skin. However, toxicity can occur, although rarely, from very high doses of vitamin D supplements.

\section{VITAMIN D AND CVD RISK FACTORS}

\section{Vitamin D and Hypertension}

Lower vitamin D levels are associated with increased risk of prevalent and incident hypertension [17, 19, 20]. In NHANES-III, participants in the highest $25(\mathrm{OH}) \mathrm{D}$ quintile had mean systolic blood pressure that was $3 \mathrm{~mm} \mathrm{Hg}$ lower compared to those in the lowest $25(\mathrm{OH}) \mathrm{D}$ quintile [21]. It was estimated that racial/ethnic differences in $25(\mathrm{OH}) \mathrm{D}$ levels explained approximately half of the increased hypertension prevalence in non-Hispanic blacks compared with whites. Among Hispanics and blacks, there was an inverse association of $25(\mathrm{OH}) \mathrm{D}$ levels with systolic and diastolic blood pressure, although adjustment for BMI attenuated this association [22].

The association of vitamin D with blood pressure is biologically plausible. In mice, vitamin D is an inhibitor of the renin-angiotensin system [23]. Vitamin D receptor knock-out mice (VDR-/VDR-) experience high rennin, angiotensin, and aldosterone levels, and as a consequence develop hypertension and cardiac hypertrophy [24]. Mice with a deletion of the 25(OHD) 1 alpha-hydroxylase gene $(1 \alpha(\mathrm{OH})$ ase $-/-)$ cannot convert $25(\mathrm{OH}) \mathrm{D}$ into the activated $1,25(\mathrm{OH}) 2 \mathrm{D}$, and similarly develop hypertension, cardiac hypertrophy, and impaired cardiac function in addition to skeletal abnormalities similar to rickets. Treatment of $1 \alpha(\mathrm{OH})$ ase -/- mice with activated vitamin $\mathrm{D}$ can normalize blood pressure, cardiac systolic function, and rennin/aldosterone levels [25]. On the other hand, treatment of $1 \alpha(\mathrm{OH})$ ase -/- knockout mice with rennin-angiotensin-aldosterone system (RAAS) pathway blockers such as captopril or lorsartan normalized blood pressure and cardiac function, but rennin remained elevated through feedback mechanisms [25].

There are a few small clinical trials that suggest vitamin D supplementation may reduce systolic blood pressure [2628]. However, larger clinical trials are needed to determine whether vitamin D can lower the risk of developing hypertension or can be an effective therapeutic agent among those with above-optimal blood pressure.

\section{Vitamin D, Obesity, and Diabetes}

Several studies have found a cross-sectional association between low levels of $25(\mathrm{OH}) \mathrm{D}$ and obesity, the metabolic syndrome, glucose intolerance, hyperinsulinemia, and type 2 diabetes [17, 29-31]. Although fat cells sequester vitamin D, the cross-sectional association of $25(\mathrm{OH}) \mathrm{D}$ deficiency with diabetes remains even after BMI, physical activity, and other potential confounding factors are taken into account [31]. Interestingly, vitamin D may also play a role in obesity, as women randomized to calcium and vitamin $\mathrm{D}$ in the Women's Health Initiative (WHI) clinical trial, experienced less weight gain compared to women on placebo [32]. Knept et al. found that in a nested case-control study from Finland that men, but not women, with higher serum vitamin D levels had a decreased risk of developing incident type 2 diabetes [33]. An explanation of the sex difference remains unclear and was not addressed by the authors. As seen in other studies, women had lower mean $25(\mathrm{OH}) \mathrm{D}$ levels than men. 
These prospective findings were also confirmed by another recent study by Forouhi et al. that found in 524 non-diabetic men and women that baseline $25(\mathrm{OH}) \mathrm{D}$ levels predicted future glycemia and insulin resistance after 10-years of followup [34]. In that study, baseline $25(\mathrm{OH}) \mathrm{D}$ levels were inversely associated with fasting glucose at 10 -years $(\beta=-$ $0.0023, \mathrm{p}=0.019), 2$-hour post-load glucose levels $(\beta=-$ 0.0097, $\mathrm{p}=0.006)$, fasting insulin $(\beta=-0.1467, \mathrm{p}=0.010)$, and HOMA-IR $(\beta=-0.0059, \mathrm{p}=0.005)$ even after adjustment for age, sex, smoking, BMI, and season [34].

The association of low vitamin D levels with diabetes has biological basis as reviewed by Mathieu et al. [35], particularly for type I diabetes. Activated vitamin D binding to its receptor located in pancreatic islet cells is thought to promote insulin secretion. Activated vitamin D also has immunomodulatory effects that lead to diabetes prevention in animal models of type I diabetes [35]. Vitamin D may also prevent insulin resistance, although the mechanism is less clear than for insulin secretion [36]. Certain vitamin D receptor polymorphisms are associated with increased risk of diabetes (as reviewed by Forouhi et al. [34]). Smaller interventional trials in humans suggest a potential benefit of vitamin D supplementation on parameters of glucose/insulin homeostasis [35, 37]. In a non-randomized observational study from Finland, vitamin D supplementation in infants was associated with reduced risk of type 1 diabetes later in life [38].

On the other hand, among women in the Nurses' Health prospective cohort study, there was no overall association of vitamin D intake with risk of incident type 2 diabetes, although there was a trend of decreasing risk for women taking $>800$ IU of vitamin D compared to those who took <400 IU of vitamin D [39]. A post-hoc analysis of the large WHI clinical trial $(n=33,951)$ found that randomization to calcium supplementation plus 400 IU of vitamin D3 daily did not reduce the risk of incident diabetes over 7 years of follow-up [40]. Furthermore, there was no change in fasting glucose, insulin, and HOMA-IR (measured only in a small subset) during follow-up for women assigned to calcium and vitamin D [40]. However, limitations of this WHI study include the low dose of vitamin D used, the concomitant therapy with calcium, and cross-contamination with controls also taking vitamin D supplementation. Thus the need for a diabetes prevention trial still remains, particularly a trial using an adequate vitamin D supplementation dose, such as $\geq 1000$ IU daily which is a dose typically needed in order to raise the serum 25(OH)D levels $>30 \mathrm{ng} / \mathrm{ml}[37]$.

\section{Vitamin D and Lipids}

Lower levels of $25(\mathrm{OH}) \mathrm{D}$ are associated with hypertriglyceridemia [17]. In a study by Perez-Castrillon et al., treatment of patients with acute coronary syndrome with atorvastatin resulted in significant decreases in cholesterol and triglyceride levels and also an increase in vitamin D levels [41]. This was not a placebo controlled clinical trial, so $25(\mathrm{OH}) \mathrm{D}$ levels may have also increased as the participants became less acutely ill the farther they were out from their clinical event. In a small study of 91 ambulatory hyperlipidemic patients not previously on lipid lowering therapy evaluated during winter months, 8-weeks of rosuvastatin treatment significantly increased both $25(\mathrm{OH}) \mathrm{D}$ levels (from a mean of 14 to a mean of $36.3 \mathrm{ng} / \mathrm{ml}, \mathrm{p}<0.001)$ and
$1,25(\mathrm{OH}) 2 \mathrm{D}$ levels (from a mean of 22.9 to $26.6 \mathrm{pg} / \mathrm{dl}$, $\mathrm{p}=0.023$ ) [42]. Again, there was no placebo group for comparison. The mechanisms to explain these results are unclear.

It has been hypothesized that the benefits of statin therapy on CVD risk reduction extend beyond their lipid lowering effects, perhaps through anti-inflammatory and endothelial protective mechanisms. Statins, interestingly, have been also shown to be associated with improved bone mass [43] and reduced fractures [44, 45]. Similarly, vitamin D increases bone mass, reduces hip fracture [46], and has antiinflammatory properties. The similarities between the benefits of vitamin D and those of statins on the cardiovascular system have been noted, and it has been hypothesized that statins may activate vitamin D receptors [47].

\section{Vitamin D and Inflammation}

Activated vitamin D has immunomodulating [48] and anti-proliferative properties [49], which may be important for the prevention of cancer and infections, as well as CVD. Preliminary studies suggest that vitamin D supplementation may decrease serum markers of inflammation. Timms et al. found that sensitive C-reactive protein (CRP) correlated inversely with $25(\mathrm{OH}) \mathrm{D}(\mathrm{r}=-0.22, \mathrm{p}=0.03)$ [50], and a few small clinical trials found that treatment with activated vitamin D lowered serum CRP levels [50-52]. Vitamin D supplementation also improved the cytokine profile among $\mathrm{CHF}$ patients [53]. However, in cross-sectional analyses of NHANES-III as well as in an Amish population, 25(OH)D levels were not associated with CRP levels after BMI and other covariates were taken into account $[31,54]$.

\section{VITAMIN D AND RENAL DISEASE}

Observational data shows that the use of activated vitamin D in patients with end-stage renal disease (ESRD) lowers the risk of mortality [55-57]. Furthermore, activated vitamin D's anti-inflammatory and anti-proliferative effects may protect against renal injury. In a rat model of glomerulonephritis, vitamin D analogs inhibit transforming growth factor beta and mesangial cell proliferation, which contribute to glomerular injury $[58,59]$. Treatment with activated vitamin D animal also decreased proteinuria in animals [60] and in one small uncontrolled clinical trial of 10 patients [61] and in 2 randomized clinical trials [52, 62]. Low levels of $25(\mathrm{OH}) \mathrm{D}$ are associated with albuminuria in a crosssectional analyses of NHANES [63]. There are currently ongoing randomized clinical trials to test the anti-proteinuric effects of vitamin D [64].

\section{VITAMIN D AND SUBCLINICAL DISEASE}

\section{Coronary Artery Calcification}

Given vitamin D's essential role in bone formation, it can be hypothesized that vitamin D may play a role in vascular calcification. There is frequently seen an inverse association between osteoporosis and vascular calcification. Animal models given excessive vitamin D do develop vascular calcification [65], although vitamin D excess is rare in humans. However experimental studies suggest vitamin D deficiency may also lead to biologic processes that facilitate vascular calcification. The physiologic plausibility for a bi-phasic 
dose-response curve for vitamin $\mathrm{D}$ in vascular calcification has been described in a review by Zittermann et al. [66].

In a group of 173 patients at moderately high risk for coronary heart disease who underwent EBCT scanning of their coronary arteries, Watson et al. found serum $1,25(\mathrm{OH}) 2 \mathrm{D}$ levels were inversely correlated with the extent of coronary artery calcification (CAC) [67]. These findings were confirmed by Doherty et al. who also found that log $1,25(\mathrm{OH}) 2 \mathrm{D}$ levels were inversely correlated with logtransformed calcium mass [68]. Levels of activated vitamin $\mathrm{D}$ did not, however, explain racial/ethnic differences in coronary artery calcium between blacks and whites in the Doherty study. However another study by Arad et al. found no correlation between serum 1,25(OH)2D levels and coronary calcification in 50 patients undergoing coronary angiography, potentially secondary to the smaller sample size [69].

Among the Old Order Amish, a founder population where confounding influences such as geography and lifestyle would expect to be minimized, we found no association of $25(\mathrm{OH}) \mathrm{D}$ levels with the risk of prevalent CAC or CAC severity [54]. In a subset of participants in the Multi-Ethnic Study of Atherosclerosis (MESA) free of clinical CVD at baseline, de Boer et al. found no cross-sectional association of $25(\mathrm{OH}) \mathrm{D}$ levels with risk of prevalent CAC after adjustment for CVD risk factors including BMI and kidney function [70]. However among these MESA participants, there was an association of $25(\mathrm{OH}) \mathrm{D}$ with risk of developing incident CAC over follow-up, an association that appeared the strongest among participants with lower estimated glomerular filtration rate (GFR) [70]. This suggests that accelerated atherosclerosis may be one mechanism by which vitamin $\mathrm{D}$ deficiency confers increased CVD risk.

\section{Carotid Intimal Medial Thickness (cIMT)}

Low 25(OH)D levels have also been associated with increased cIMT, another marker of subclinical vascular disease, in a diabetic population [71]. However, among the Amish population, similar to our findings with CAC, we found no cross-sectional association of 25(OH)D levels with common cIMT [54]. This was in contrast to the Rancho Bernado cohort study of older adults (who generally have higher vitamin $\mathrm{D}$ levels than many of the other prospective cohorts described due their residence in a sunny and temperate year-round climate) where we found that 25(OH)D levels inversely correlated with internal cIMT but not common cIMT [72]. We hypothesized that internal cIMT may be a better marker of atherosclerosis whereas common cIMT may reflect more vascular changes from sheer stress.

\section{Peripheral Arterial Disease (PAD)}

Among ambulatory participants of NHANES 2001-2004, low serum 25(OH)D levels are associated with a higher prevalence of PAD after demographics, known CVD risk factors, physical activity, were taken into account, while there was no association of calcium, phosphate, and iPTH with PAD [73]. As discussed earlier, blacks are at greater risk for vitamin D deficiency, as well as at greater risk of PAD - an association that is not entirely explained by differences in traditional risk factors. We estimated that approximately a third of the excess risk of PAD conferred by black race can be explained by differences in vitamin $\mathrm{D}$ levels [74]. Whether treatment with activated vitamin D can prevent PAD or mediators such as diabetes is unknown. Among patients with type 2 diabetes, treatment with activated vitamin D did improve brachial artery flow mediated dilation, a marker of endothelial function, independent of changes in blood pressure [28].

\section{Left Ventricular Hypertrophy (LVH)}

As mentioned previously, mice with either VDR knockout or knock-out of 1-hydroxylase gene develop hypertension and cardiac hypertrophy [24, 25]. In 2 small clinical trials of hemodialysis patients treated with activated vitamin D, regression of LVH was observed [75, 76].

\section{VITAMIN D, CVD EVENTS, AND MORTALITY}

Recent observational cohort studies have found a consistent association between low levels of $25(\mathrm{OH}) \mathrm{D}$ with cardiovascular events including stroke, congestive heart failure, CVD mortality, and all-cause mortality as discussed below.

\section{Myocardial Infarction}

As early as the 1990's, a small community-based casecontrol study in New Zealand found that 173 men with myocardial infarction had lower $25(\mathrm{OH}) \mathrm{D}$ levels compared to matched controls [77]. This inverse association of $25(\mathrm{OH}) \mathrm{D}$ levels and risk of myocardial infarction was confirmed more recently in a larger nested-case control study of men from the Health Professional Followup Study, an association that remained after controlling for known CVD risk factors [78]. On the other hand, a small case-control study by Rajasree et al. found in 143 patients with ischemic heart disease that very elevated $25(\mathrm{OH}) \mathrm{D}$ levels $(>89 \mathrm{ng} / \mathrm{ml})$ conferred a multivariate adjusted OR of 3.18 (95\% CI 1.31-7.73), suggesting that there may be an optimal range with very high levels actually being harmful [79].

\section{Stroke}

A small case-control study of 44 stroke patients found that cases had lower $25(\mathrm{OH}) \mathrm{D}$ levels than healthy elderly controls [80]. In the Ludwigshafen Risk and Cardiovascular Health (LURIC) prospective study of 3316 individuals referred for coronary angiography at a single center in Germany, low levels of both $25(\mathrm{OH}) \mathrm{D}$ and $1,25(\mathrm{OH}) 2 \mathrm{D}$ predicted incident stroke during a median of 8 years of followup [81].

\section{Congestive Heart Failure (CHF)}

Vitamin D receptor knock-out mice develop signs of congestive heart failure, and treatment with activated vitamin $\mathrm{D}$ reduces cardiac hypertrophy and left ventricular diameter among a hypertensive-CHF rat model [82]. These CHF effects may be independent of vitamin D's role in the reninangiotensin system [83], and may in part be mediated by vitamin D modulation of matrix metalloproteinases (MMPs) and tissue inhibitors of metalloproteinases (TIMPs), key components of the extracellular matrix metabolism that contribute to left ventricular re-modeling and dilation in $\mathrm{CHF}$ [84]. Again in that same German LURIC cohort that prospectively followed individuals referred for coronary angi- 
ography, low levels of $25(\mathrm{OH}) \mathrm{D}$ and $1,25(\mathrm{OH}) 2 \mathrm{D}$ were associated with increased risk of death from heart failure or sudden cardiac death [85]. 25(OH)D levels were also inversely correlated with pro-B-natriuretic peptide and New York Heart Association classes [85]. Among patients with end-stage heart failure, lower circulating calcitriol levels was associated with poor outcomes despite adjustment for many clinical predictors [86], although residual confounding and reverse causation (i.e. the sickest patients have the lowest vitamin D levels) could still in part account for the association. Patients with CHF vs healthy controls differ in many lifestyle factors that may influence their vitamin D status (such as participation in sports clubs, taking summer holidays, etc) [87] - factors that are typically not adequately controlled for in multivariable regression models.

\section{CVD Combined Events}

Among the Framingham Offspring Study of individuals free of prior CVD, those with 25(OH)D levels $<15 \mathrm{ng} / \mathrm{ml}$ had increased risk of incident CVD events (including fatal or non-fatal myocardial infarction, coronary insufficiency, fatal or non-fatal cerebrovascular events, claudication, or heart failure) [HR 1.62 (95\% CI 1.11-2.36)] compared to those with levels $\geq 15 \mathrm{ng} / \mathrm{ml}$, after adjustment for age and conventional risk factors [88]. Further adjustment for physical activity, hsCRP, or vitamin supplementation use did not attenuate these results.

\section{Mortality}

Our group found that, among 13,331 US adults participating in NHANES-III, those in the lowest quartile of $25(\mathrm{OH}) \mathrm{D}$ [levels $<18 \mathrm{ng} / \mathrm{ml}$ ] compared to the highest quartile had a $26 \%$ increased risk of all-cause mortality during a median of 8.7 years of follow-up after traditional risk factors, renal disease, socioeconomic factors, and lifestyle factors were taken into account [31]. The association of low 25(OH)D levels with mortality was strongest in those without CVD, without hypertension, and without diabetes mellitus, and in women arguing against low vitamin D levels being just a marker of poor general health. The fact that the associations were stronger in those without CVD at baseline suggests that if a causal relationship exists, $25(\mathrm{OH}) \mathrm{D}$ deficiency may play a role before CVD is established. In the NHANES-III study, there was also a trend towards lowvitamin D levels being associated with CVD mortality as well with similar magnitude of association (i.e. mortality rate ratio) which did not meet statistical significance. However in a follow-up study by Ginde AA et al. evaluating only the NHANES-III participants $>65$ years of age, the authors found that severe vitamin D deficiency $<10 \mathrm{ng} / \mathrm{ml}$ was associated with both all-cause and CVD mortality but a stronger association for CVD mortality than non-CVD mortality (HR of 2.36, 95\% CI 1.17-4.75 vs HR 1.42, 0.73-2.79 for subjects with levels $<10 \mathrm{ng} / \mathrm{ml}$ compared to levels $>40 \mathrm{ng} / \mathrm{ml}$ ) [89].

Similarly another prospective cohort study of older adults (the Hoorn Study) found that low 25(OH)D was independently associated with all-cause mortality and an even stronger association with CVD mortality (HR 2.24 95\% CI 1.28-3.92 and HR 4.78 95\% CI 1.95-11.69, respectively for the lowest quartile compared to the upper three $25(\mathrm{OH}) \mathrm{D}$ quartiles) [90].
Low 25(OH)D levels and low 1,25(OH)2D levels were both also independently associated with all-cause and CVD mortality in the German LURIC; these findings remained significant even after adjustment for the other vitamin D metabolite and iPTH levels [91]. Furthermore, risk of mortality was highest among those who fell in the lowest quartile of both $25(\mathrm{OH}) \mathrm{D}$ and $1,25(\mathrm{OH}) 2 \mathrm{D}$ compared to low levels of either metabolite alone, suggesting a synergistic effect of both metabolites taken together on CVD risk, despite the fact that the two metabolites were generally weakly correlated with each other $(\mathrm{r}=0.36)$. This suggests that $25(\mathrm{OH}) \mathrm{D}$ and $1,25(\mathrm{OH}) 2 \mathrm{D}$ may have independent biologic effects, with perhaps $25(\mathrm{OH}) \mathrm{D}$ being important for local conversion to the activated metabolite in extra-renal tissues for autocrine/ paracrine effects.

In both the Framingham cohort study [88] and in the overall NHANES-III study [31], there was a suggestion of a U-shaped curve with a trend towards increased risk for CVD and mortality at high levels of $25(\mathrm{OH}) \mathrm{D}$, which did not meet statistical significance as few individuals had very high $25(\mathrm{OH}) \mathrm{D}$ levels. This finding was more pronounced in women in NHANES [31], another thus far unexplained sex difference. Animal models suggest that animals fed a vitamin-D and cholesterol rich diet have accelerated atherosclerosis $[65,92,93]$. These studies, along with the case-control study described above by Rajasree [79], raises the concern that there may be an optimal range for $25(\mathrm{OH}) \mathrm{D}$, such that both low and high levels may increase risk for mortality.

\section{Vitamin D Supplementation and CVD Outcomes}

In generally healthy post-menopausal participants of the Women's Health Initiative (WHI), vitamin D supplementation (200 IU plus $500 \mathrm{mg}$ calcium twice daily) did not reduce CVD risk over 7 year average follow-up [94]; although it is widely agreed that the supplementation dose was inadequate for the normal adult requirement of at least 800 IU daily of vitamin D [95]. Also the placebo arm was allowed to continue their vitamin supplements which may have blunted any differences between the treated and the control groups. Furthermore 25(OH)D levels were not measured at baseline for all women in that trial; thus, whether vitamin D supplementation at higher doses can reduce CVD risk among those with documented vitamin D deficiency is unknown. Another randomized clinical trial of calcium supplementation without vitamin D among post-menopausal women in New Zealand actually showed an increased risk of stroke in the calcium treated arm [96]. Although participants in that study were randomly allocated to supplementation or placebo, there appeared to be baseline imbalances between groups with a slightly higher percentage of hypertension, current and former smoking, previous ischemic heart disease, previous stroke, total and LDL cholesterol, and dyslipidemia in the calcium arm. This may have influenced the higher outcomes seen among those assigned to calcium supplementation. In addition, the investigators did not report baseline serum vitamin D levels, except to say they excluded those with very severe vitamin D deficiency (less than $10 \mathrm{ng} / \mathrm{ml}$ ); it is possible that this population may have adequate or perhaps even high levels of serum vitamin D. Calcium plus high levels of vitamin D could theoretically lead to vascular calcifications similar to animal models. While vitamin D may be beneficial 
for cardiovascular health, supplementation with calcium alone (without vitamin D) may not be.

However, a meta-analysis of 18 randomized clinical trials, including the Women's Health Initiative, did show that participants randomized to vitamin D supplementation experienced fewer deaths compared to those randomized to placebo [97]. This meta-analysis included information from over 57,000 participants, mostly post-menopausal women, with a mean daily vitamin $\mathrm{D}$ dose of $528 \mathrm{IU}$. The relative risk for all-cause mortality was 0.93 (95\% CI: 0.87-0.99).

\section{CLINICAL PERSPECTIVES, UNANSWERED QUES- TIONS, AND FUTURE DIRECTIONS}

Many of the analyses from cross-sectional and case/control observational studies bring up concern that the associations found between vitamin D and CVD might be explained at least in part by residual confounding and/or reverse causation (i.e. the sickest patients are the least likely to exercise and get out in the sunlight). While these studies attempt to adjust for many clinical predictors and known CVD risk factors, it is very difficult to adequately take into account factors of "good health" vs "poor health" during statistical adjustment. The prospective cohort studies add supportive strength to the implication that low vitamin D levels may in fact be causally related to CVD outcomes. But despite the fact that many of these cohorts had vitamin D levels measured many years before the outcome assessment, the possibility remains that subtle differences in poorer health state may explain in part the results. As mentioned above, CHF patients and healthy controls differed in many lifestyle factors that could influence vitamin D [87]. Furthermore, individuals with higher vitamin D levels could walk farther distances on a 6-minute walk and had lower frailty scores, suggesting a healthier, more ambulatory phenotype [98].

These observational prospective studies are based on a one-time measurement of $25(\mathrm{OH}) \mathrm{D}$ at baseline. While ideally this would reduce concerns of reverse causation as the individuals screened were generally healthy ambulatory participants at the time of $25(\mathrm{OH}) \mathrm{D}$ measurements and then followed forward in time for incident events, lifetime patterns of vitamin D status including changes in vitamin D levels over time have not been assessed. However Dobnig et $a l$. did find that among 100 healthy older individuals participating in a fall prevention study that $25(\mathrm{OH}) \mathrm{D}$ levels measured 12 months apart were highly correlated $(\mathrm{r}=0.76$, $\mathrm{p}<0.004)$ [91].

There is significant biologic plausibility of the role that vitamin D plays in cardiovascular health as detailed above. Right now there is convincing evidence that low vitamin D levels is a good predictor of risk for adverse CVD outcomes independent of traditional CVD risk factors, similar to the risk prediction ability of hsCRP and other biomarkers. However similar to the other biomarkers, it is not clear whether vitamin $\mathrm{D}$ is a casual agent or simply a surrogate marker for poorer health states. If vitamin $\mathrm{D}$ is only a marker of some other poorly measured aspect of CVD risk, vitamin D supplementation may not correct the risk state. If the relationship between low 25(OH)D and CVD risk is causal, incident diabetes may be one mediator in a causal pathway that is likely multifactorial, with other potential mechanisms in- cluding inflammation, incident hypertension, left ventricular hypertrophy and/or regulation of the rennin/angiotensin pathway as described above.

Therefore further clinical trials of vitamin D supplementation at adequate doses are needed to show whether vitamin $\mathrm{D}$ treatment can actually prevent or delay the progression of CVD events and/or incident diabetes. This question hopefully will be answered by the planned Vitamin D and Omega-3 Trial (VITAL) lead by Drs JoAnn Manson and Julie Buring (Harvard Medical School/ Brigham and Women's Hospital, Boston, MA) which will begin recruitment in January 2010 and plans to run for five years [99]. The objective of this large, National Institutes of Healthsponsored study is to determine whether vitamin-D and/or omega-3 fatty-acid supplementation can reduce the risk of developing heart disease, stroke, or cancer. The study is aiming to enroll 20,000 men $>60$ years and women $>65$ years of age, one-quarter of whom will be black, to further investigate the potential racial/ethnic disparity in CVD outcomes hypothesized to be linked to vitamin D. The study design is multifactorial as participants will be randomized to daily vitamin D (2000 IU) and fish oil (1 g), daily vitamin D and fish-oil placebo, daily vitamin-D placebo and fish oil, or daily vitamin-D placebo and fish-oil placebo.

The VITAL trial will hopefully provide the evidencebased medicine regarding vitamin D supplementation that is currently lacking in the literature; however there are some concerns among experts in the field that this clinical trial may not adequately provide conclusive evidence on this issue. For one, serum 25(OH)D levels will not be measured in everyone at baseline, and thus enrollment is not based on documented vitamin D deficiency. Supplementation, in theory, may only benefit those who are actually deficient to restore $25(\mathrm{OH}) \mathrm{D}$ values in the normal range and may be harmful in those rare individuals with very high $25(\mathrm{OH}) \mathrm{D}$ levels. For those who are truly deficient, 2000 IU per day still may not be adequate enough to raise serum vitamin D levels into the recommended range. Usually 50,000 IU per week for 8 weeks is the recommended repletion dose for those with deficiency, with 1000-2000 IU of vitamin D daily as a maintenance dose [10]. Also, only older participants are being recruited into VITAL, a group which in theory may be "too late" to prevent events. While older participants are most likely to have cardiac events, if vitamin D deficiency is causally related to the development of atherosclerosis or potential intermediate factors, such as hypertension and diabetes, vitamin D supplementation may have the most benefit in those who have yet to develop these conditions (i.e., younger adults). However, the cost constraints dictate the need to do the trial in adults more likely to have events (i.e. older adults).

\section{CONCLUSION}

In summary, the experimental and observational studies described above had identified vitamin D as playing a pivotal role in many aspects of cardiovascular health. While vitamin $\mathrm{D}$ deficiency is easy to screen for, and treatment in the form of supplementation and modest sunlight exposure exists, we await results of clinical trials such as the VITAL study to determine whether vitamin D treatment can actually prevent CVD events before prevention guidelines regarding 
widespread screening and treatment strategies can be implemented.

\section{ACKNOWLEDGEMENTS}

EDM is supported by a Career Development Award from the American College of Cardiology made possible through an unrestricted educational grant from Pfizer, Inc. EDM is also supported through a Clinician Scientist Award at Johns Hopkins University. MLM is supported by grant K23078774 from the National Institute of Diabetes, Digestive and Kidney Diseases and from an American Heart Association Clinically Applied research grant.

\section{REFERENCES}

[1] Streeten, E.A.; Levine, M.A. Vitamin D metabolism or action. In: Principles and Practice of Medical Genetics; $4^{\text {th }}$ ed. Emery, A.E.; Rimoin, D.; Eds.; Churchill Livingston: New York 2002; pp. 25662623.

[2] Spina, C.S.; Tangpricha, V.; Uskokovic, M.; Adorinic, L.; Maehr, H.; Holick, M.F. Vitamin D and cancer. Anticancer Res., 2006, 26(4A), 2515-2524.

[3] Yamshchikov, A.V.; Desai, N.S.; Blumberg, H.M.; Ziegler, T.R.; Tangpricha, V. Vitamin D for treatment and prevention of infectious diseases: a systematic review of randomized clinical trials. Endocr. Pract., 2009, 15(5), 438-449.

[4] Szodoray, P.; Nakken, B.; Gaal, J.; Jonsson, R.; Szegedi, A.; Zold, E.; Szegedi, G.; Brun, J.G.; Gesztelyi, R.; Zeher, M.; Bodolay, E. The complex role of vitamin D in autoimmune diseases. Scan. J. Immunol., 2008, 68(3), 261-269.

[5] Agarwal, R. Vitamin D, proteinuria, diabetic nephropathy, and progression of CKD. Clin. J. Am. Soc. Nephrol., 2009, 4, 15231528.

[6] Zitterman, A; Schleithoff, S.S.; Koerfer, R. Putting cardiovascular disease and vitamin D insufficiency into perspective. Br. J. Nutr., 2005, 94, 483-492.

[7] Lee, J.H.; O’Keefe, J.H.; Bell, D.; Hensrud, D.D.; Holick, M.F. Vitamin D deficiency: An important, common, and easily treatable cardiovascular risk factor. J. Am. Coll. Cardiol., 2008, 52, 19491956.

[8] Lim, H.S.; Roychoudhuri, R.; Peto, J.; Schwartz, G.; Baade, P.; Moller, H. Cancer survival is dependent on season of diagnosis and sunlight exposure. Int. J. Cancer, 2006, 119(7), 1530-1536.

[9] Holick, M.F. Vitamin D deficiency. N. Engl. J. Med., 2007, 357, 266-281.

[10] Holick, M.F.; Chen, T.C. Vitamin D deficiency: a worldwide problem with health consequences. Am. J. Clin. Nutr., 2008, 87 (suppl), 1080S-6S.

[11] Hewison, M.; Burke, F.; Evans, K.N.; Lammas, D.A.; Sansom, D.M.; Liu, P.; Modlin, R.L.; Adams, J.S. Extra-renal 25hydroxyvitamin D3-1alpha-hydroxylase in human health and disease. J. Steroid Biochem. Mol. Biol., 2007, 103(3-5), 316-321.

[12] Dawson-Hughes, B.; Heaney, R.P.; Holick, M.F.; Lips, P.; Meunier, P.J.; Vieth, R. Estimates of optimal vitamin D status. Osteoporos. Int., 2005, 16, 713-716.

[13] Zadshir, A.; Tareen, N; Pan, D.; Norris, K.; Martins, D. The prevalence of hypovitaminosis D among US adults: data from NHANES III. Ethn. Dis., 2005, 15(S5), 97-101.

[14] Ginde, A.A.; Liu, M.C.; Camargo, C.A. Jr. Demographic differences and trends of vitamin D insufficiency in the US population, 1988-2004. Arch. Intern. Med., 2009, 169(6), 626-632.

[15] Looker, A.C.; Pfeiffer, C.M.; Lacher, D.A.; Schleicher, R.L.; Picciano, M.F.; Yetley, E.A. Serum 25-hydroxyvitamin D status of the US population: 1988-1994 compared with 2000-2004. Am. J. Clin. Nutr., 2008, 88(6), 1519-1527.

[16] Looker, A.C.; Lacher, D.A.; Pfeiffer, C.M.; Schleicher, R.L.; Picciano, M.F.; Yetley, E.A. Data advisory with regard to NHANES serum 25-hydroxyvitamin D data. Am. J. Clin. Nutr., 2009, 90(3), 695.

[17] Martins, D.; Wolf, M.; Pan, D.; Zadshir, A.; Tareen, N.; Thadhani, R.; Felsenfeld, A.; Levine, B.; Mehrotra, R.; Norris, K. Prevalence of cardiovascular risk factors and the serum levels of 25hydroxyvitamin D in the United States: Data from the third national health and nutrition examination survey. Arch. Intern. Med., 2007, 167(11), 1159-1165.

[18] Scragg, R.; Camargo, C.A. Frequency of leisure-time physical activity and serum 25-hydroxyvitamin D levels in the US population: Results from the Third National Health and Nutrition Examination Survey. Am. J. Epidemiol., 2008, 168, 577-586.

[19] Forman, J.P.; Bischoff-Ferrari, H.A.; Willett, W.C.; Stampfer, M.J., Curhan, G.C. Vitamin D intake and risk of incident hypertension: results from three large prospective cohort studies. Hypertension, 2005, 46(4), 676-682.

[20] Forman, J.P.; Giovannucci, E.; Holmes, M.D.; Bischoff-Ferrari, H.A.; Tworoger, S.S.; Willett, W.C.; Curhan, G.C. Plasma 25hydroxyvitamin D levels and the risk of incident hypertension. $\mathrm{Hy}$ pertension, 2007, 49, 1063-1069.

[21] Scragg, R.; Sower, M.; Bell, C. Serum 25-hydroxyvitamin D, ethnicity, and blood pressure in the Third National Health and Nutrition Examination Survey. Am. J. Hypertens., 2007, 20(7), 713-719.

[22] Schmitz, K.J.; Skinner, H.G.; Bautista, L.E.; Fingerlin, T.E.; Langefeld, C.D.; Hicks, P.J.; Haffner, S.M.; Bryer-Ash, M.; Wagenknecht, L.E., Bowden, D.W.; Norris, J.M.; Engelman, C.D. Association of 25-hydroxyvitamin D with blood pressure in predominantly 25-hydroxyvitamin D deficient Hispanic and African Americans. Am. J. Hypertens., 2009, 22(8), 867-870.

[23] Li, Y.C.; Kong, J.; Wei, M; Chen, Z.F.; Liu, S.Q.; Cao, L.P. 1,25Dihydroxyvitamin $\mathrm{D}(3)$ is a negative endocrine regulator of the renin-angiotensin system. J. Clin. Invest., 2002, 110(2), 229-238.

[24] Xiang, W.; Kong, J.; Chen, S.; Cao, L.P.; Qiao, G.; Zheng, W.; Liu, W.; Li, X.; Gardner, D.G.; Li, Y.C. Cardiac hypertrophy in vitamin $\mathrm{D}$ receptor knockout mice: role of the systemic and cardiac reninangiotensin systems. Am. J. Physiol. Endocrinol. Metab., 2005, 288(1), E125-132.

[25] Zhou, C.; Lu, F.; Cao, K.; Xu, D.; Goltzman, D; Miao, D. Calciumindependent and 1,25(OH)2D3-dependent regulation of the renninangiotensin system in $1 \alpha$-hydroxylase knockout mice. Kidney Int., 2008, 74, 170-179.

[26] Krause, R.; Buhring, M.; Hopfenmuller, W.; Holick, M.F., Sharma, A.M. Ultraviolet B and blood pressure. Lancet, 1998, 352(9129), 709-710.

[27] Pfeifer, M.; Begerow, B.; Minne, H.W.; Nachtigall, D.; Hansen, C. Effects of a short-term vitamin $\mathrm{D}(3)$ and calcium supplementation on blood pressure and parathyroid hormone levels in elderly women. J. Clin. Endocrinol. Metab., 2001, 86(4), 1633-1637.

[28] Sugden, J.A.; Davies, J.I.; Witham, M.D.; Morris, A.D.; Struthers, A.D. Vitamin D improves endothelial function in patients with type 2 diabetes mellitus and low vitamin D levels. Diabet. Med., 2008, 25(3), 320-325.

[29] Ford, E.S.; Ajani, U.A.; McGuire, L.C.; Liu, S. Concentrations of serum vitamin D and the metabolic syndrome among US adults. Diabetes Care, 2005, 28, 1228-1230.

[30] Baynes, K.C.; Boucher, B.J.; Feskens, E.J.; Kromhout, D. Vitamin $\mathrm{D}$, glucose intolerance, and insulinemia in elderly men. Diabetologia, 1997, 40, 344-347.

[31] Melamed, M.L.; Michos, E.D.; Post, W.; Astor, B. $25-$ hydroxyvitamin D levels and the risk of mortality in the general population. Arch. Intern. Med., 2008, 168(15), 1629-1637.

[32] Caan, B.; Neuhouser, M.; Aragaki, A.; Lewis, C.B.; Jackson, R.; LeBoff, M.S.; Margolis, K.L.; Powell, L.; Uwaifo, G.; Whitlock, E.; Wylie-Rosett, J.; LaCroix, A. Calcium plus vitamin D supplementation and the risk of postmenopausal weight gain. Arch. Intern. Med., 2007, 167(9), 893-902.

[33] Knekt, P.; Laaksonen, M.; Mattila, C.; Härkänen, T.; Marniemi, J.; Heliövaara, M.; Rissanen, H.; Montonen, J.; Reunanen, A. Serum vitamin D and subsequent occurrence of type 2 diabetes. Epidemiology, 2008, 19, 666-671.

[34] Forouhi, N.G.; Luan, J.; Cooper, A.; Boucher, B.J.; Wareham, N.J. Baseline serum 25-hydroxyvitamin D is predictive of future glycemic status and insulin resistance: the Medical Research Council Ely Prospective Study 1990-2000. Diabetes, 2008, 57(10), 2619-2625.

[35] Mathieu, C.; Gysemans, G.; Giulietti, A.; Bouillon, R. Vitamin D and diabetes. Diabetologia, 2005, 48, 1247-1257.

[36] Chiu, K.C.; Chu, A.; Go, V.L.; Saad, M.F. Hypovitaminosis D is associated with insulin resistance and beta cell dysfunction. Am. J. Clin. Nutr., 2004, 79, 820-825.

[37] Scragg, R. Vitamin D and type 2 diabetes: are we ready for a prevention trial? Diabetes, 2008, 57, 2565-2566. 
[38] Hypponen, E.; Laara, E.;, Reunanen, A.; Jarvelin, M.R.; Virtanen, S.M. Intake of vitamin D and risk of type I diabetes: a birth-cohort study. Lancet, 2001, 358(9292), 1500-1503.

[39] Pittas, A.G.; Dawson-Hughes, B., Li, T.; Van Dam, R.M.; Willett, W.C., Manson, J.E., Hu, F.B. Vitamin D and calcium intake in relation to type 2 diabetes in women. Diabetes Care, 2006, 26(3), 650-656.

[40] de Boer, I.H.; Tinker, L.F.; Connelly, S.; Curb, J.D.; Howard, B.V.; Kestenbaum, B.; Larson, J.C.; Manson, J.E.; Margolis, K.L.; Siscovick, D.S.; Weiss, N.S. Women's Health Initiative Investigators. Calcium plus vitamin D supplementation and the risk of incident diabetes in the Women's Health Initiative. Diabetes Care, 2008, 31, 701-797.

[41] Perez-Castrillon, J.L.; Vega, G.; Abad, L.; Sanz, A.; Chaves, J.; Hernandez, G.; Duenas, A. Effects of atorvastatin on vitamin D levels in patients with acute ischemic heart disease. Am. J. Cardiol., 2007, 99(7), 903-905.

[42] Yavuz, B.; Ertugrul, D.T.; Cil, H.; Ata, N.; Akin, K.O.; Yalcin, A.A.; Kucukazman, M.; Dal, K.; Hokkaomeroglu, M.S.; Yavuz, B.B.; Tutal, E. Increased levels of 25 hydroxyvitamin D and 1,25dihydroxyvitamin $\mathrm{D}$ after rosuvastatin treatment: a novel pleiotropic effect of statins? Cardiovasc. Drug Ther., 2009, 23(4), 295299.

[43] Garrett, I.R.; Gutierrez, G.; Mundy, G.R. Statins and bone formation. Curr. Pharm. Des., 2001, 7, 715-736.

[44] Wang, P.S.; Solomon, D.H.; Mogun, H.; Avorn, J. HMG-CoA reductase inhibitors and the risk of hip fractures in elderly patients. JAMA, 2000, 382, 3211-3216.

[45] Rejnmark, L.; Olsen, M.L.; Johnsen, S.P.; Vestergaard, P.; Sørensen, H.T.; Mosekilde L. Hip fracture risk in statin users-a population based Danish case-control study. Osteoporos. Int., 2004, $15,452-458$

[46] Dawson-Hughes, B.; Harris, S.S.; Krall, E.A.; Dallal, G.E. Effect of calcium and vitamin D supplementation on bone density in men and women 65 years of age or older. N. Engl. J. Med., 1997, 337(10), 670-6.

[47] Grimes, D.S. Are statins analogues of vitamin D? Lancet, 2006, 368, 83-86.

[48] Mathieu, C.; Adorini, L. The coming of age of 1,25 dihydroxyvitamin D3 analogs as immunomodulatory agents. Trends Mol Med., 2002, 8, 174-178.

[49] Banerjee, P.; Chatterjee, M. Antiproliferative role of vitamin D and its analogs--a brief overview. Mol Cell Biochem., 2003, 253(1-2), 247-254.

[50] Timms, P.M.; Mannan, N.; Hitman, G.A.; Noonan, K.; Mills, P.G.; Syndercombe-Court, D.; Aganna, E.; Price, C.P.; Boucher, B.J. Circulating MMP9, vitamin D, and variation in the TIMP-1 response with VDR genotype: mechanisms for inflammatory damage in chronic disorders? QJM, 2002, 95, 787-796.

[51] Van den Berghe, G.; Van Roosbroeck, D.; Vanhove, P.; Wouters, P.J.; De Pourcq, L.; Bouillon, R. Bone turnover in prolonged critical illness: effect of vitamin D. J. Clin. Endocrinol. Metab., 2003, 88, 4623-4632.

[52] Alborzi, P.; Patel, N.A.; Peterson, C.; Bills, J.E.; Bekele, D.M.; Bunaye, Z.; Light, R.P.; Agarwal, R. Paricalcitol reduces albuminuria and inflammation in chronic kidney disease: a randomized double-blind pilot trial. Hypertension, 2008, 52(2), 249-255.

[53] Schleithoff, S.S.; Zittermann, A.; Tenderich, G.; Berthold, H.K.; Stehle, P.; Koerfer, R. Vitamin D supplementation improves cytokine profiles in patients with congestive heart failure: a doubleblind, randomized, placebo-controlled trial. Am. J. Clin. Nutr., 2006, 83(4), 754-759.

[54] Michos, E.D.; Streeten, E.A.; Ryan, K.A.; Rampersaud. E.; Peyser, P.A.; Bielak, L.F.; Shuldiner, A.R.; Mitchell, B.D.; Post, W. Serum 25-hydroxyvitamin D levels are not associated with subclinical vascular disease or C-reactive protein in the Old Order Amish. Calcific Tissue Int., 2009, 84(3), 195-202.

[55] Teng, M.; Wolf, M.; Ofsthun, M.N.; Lazarus, J.M.; Hernán, M.A.; Camargo, C.A. Jr; Thadhani, R. Activated injectable vitamin D and hemodialysis survival: a historical cohort study. J. Am. Soc. Nephrol., 2005, 16(4), 1115-1125.

[56] Melamed, M.L.; Eustace, J.A.; Plantinga, L.; Jaar, B.G.; Fink, N.E.; Coresh, J.; Klag, M.J.; Powe, N.R. Changes in serum calcium, phosphate, and PTH and the risk of death in incident dialysis patients: a longitudinal study. Kidney Int., 2006, 70(2), 351-357.
[57] Tentori, F.; Hunt, W.C.; Stidley, C.A.; Rohrscheib, M.R.; Bedrick, E.J.; Meyer, K.B.; Johnson, H.K.; Zager, P.G.; Medical Directors of Dialysis Clinic Inc. Mortality risk among hemodialysis patients receiving different vitamin D analogs. Kidney Int., 2006, 70(10), 1858-1865.

[58] Makibayashi, K.; Tatematsu, M.; Hirata, M.; Fukushima, N.; Kusano, K.; Ohashi, S.; Abe, H.; Kuze, K.; Fukatsu, A.; Kita, T.; Doi, $\mathrm{T}$. A vitamin $\mathrm{d}$ analog ameliorates glomerular injury on rat glomerulonephritis. Am. J. Pathol., 2001, 158, 1733-1741.

[59] Aschenbrenner, J.K.; Sollinger, H.W.; Becker, B.N.; Hullett, D.A. $1,25-(\mathrm{oh}(2)) \mathrm{d}(3)$ alters the transforming growth factor beta signaling pathway in renal tissue. J. Surg. Res., 2001, 100, 171-175.

[60] Migliori, M.; Giovannini, L.; Panichi, V.; Filippi, C.; Taccola, D.; Origlia, N.; Mannari, C.; Camussi, G. Treatment with 1,25dihydroxyvitamin $\mathrm{d} 3$ preserves glomerular slit diaphragmassociated protein expression in experimental glomerulonephritis. Int. J. Immunopathol. Pharmacol., 2005, 18, 779-790.

[61] Szeto, C.C.; Chow, K.M.; Kwan, B.C.; Chung, K.Y.; Leung, C.B.; $\mathrm{Li}, \mathrm{P} . \mathrm{K}$. Oral calcitriol for the treatment of persistent proteinuria in immunoglobulin A nephropathy: an uncontrolled trial. Am. J. Kidney Dis., 2008, 51, 724-731.

[62] Agarwal, R.; Acharya, M.; Tian, J.; Hippensteel, R.L.; Melnick, J.Z.; Qiu, P.; Williams, L.; Batlle, D. Antiproteinuric effect of oral paricalcitol in chronic kidney disease. Kidney Int., 2005, 68(6), 2823-2838.

[63] de Boer, I.H.; Ioannou, G.N.; Kestenbaum, B.; Brunzell, J.D.; Weiss, N.S. 25-hydroxyvitamin d levels and albuminuria in the third national health and nutrition examination survey (NHANES III). Am. J. Kidney Dis., 2007, 50, 69-77.

[64] Lambers, H.H.J.; Agarwal, R.; Coyne, D.W.; Parving, H.H.; Ritz, E.; Remuzzi, G.; Audhya, P.; Amdahl, M.J.; Andress, D.L.; de Zeeuw, D. The selective vitamin D receptor activator for albuminuria lowering (VITAL) study: study design and baseline characteristics. Am. J. Nephrol., 2009, 30(3), 280-286.

[65] Fleckenstein-Grun, G.; Thimm, F.; Frey, M.; Matyas, S. Progression and regression by verapamil of vitamin D3-induced calcific medial degeneration in coronary arteries of rats. J. Cardiovasc. Pharmacol., 1995, 26, 207-13.

[66] Zittermann, A.; Schleithoff, S.S.; Koerfer, R. Vitamin D and vascular calcification. Curr. Opin. Lipidol., 2007, 18, 41-46.

[67] Watson, K.E.; Abrolat, M.L.; Malone, L.L., Hoeg, J.M.; Doherty, T.; Detrano, R.; Demer, L.L. Active serum vitamin D levels are inversely correlated with coronary calcification. Circulation, 1997, 96, 1755-1760.

[68] Doherty, T.M.; Tang, W.; Dascalos, S.; Watson, K.E.; Demer, L.L.; Shavelle, R.M.; Detrano, R.C. Ethnic origin and serum levels of 1alpha,25-dihydroxyvitamin D3 are independent predictors of coronary calcium mass measured by electron-beam computed tomography. Circulation, 1997, 96, 1477-1481.

[69] Arad, Y.; Spadaro, L.A.; Roth, M.; Scordo, J.; Goodman, K.; Sherman, S.; Lerner, G.; Newstein, D.; Guerci, A.D. Serum concentration of calcium, 1, 25 vitamin D and parathyroid hormone are not correlated with coronary calcifications. An electron beam computed tomography study. Coron Artery Dis., 1998, 9, 513-518.

[70] de Boer, I.H.; Kestenbaum, B.; Shoben, A.B.; Michos, E.D.; Sarnak, M.J.; Siscovick, D.S. 25-hydroxyvitamin D levels inversely associate with risk for developing coronary artery calcium. J. Am. Soc. Nephrol., 2009, 20(8), 1805-1812.

[71] Targher, G.; Bertolini, L.; Padovani, R.; Zenari, L.; Scala, L.; Cigolini, M.; Arcaro, G. Serum 25-hydroxyvitamin D3 concentrations and carotid artery intima-media thickness among type 2 diabetic patients. Clin. Endocrinol., 2006, 65, 593-597.

[72] Reis, J.P.; von Muhlen, D.; Michos, E.D.; Miller III, E.R.; Appel, L.J.; Araneta, M.R.; Barrett-Connor, E. Serum vitamin D, parathyroid hormone levels, and carotid atherosclerosis. Atherosclerosis, 2009, 207(2), 585-590.

[73] Melamed, M.L.; Muntner, P.; Michos, E.D.; Uribarri, J.; Weber, C.; Sharma, J.; Raggi, P. Serum 25-hydroxyvitamin D levels and the prevalence of peripheral arterial disease: results from NHANES 2001 to 2004. Arterioscler. Thromb. Vasc. Biol., 2008, 28, 11791185.

[74] Reis, J.P.; Michos, E.D.; von Muhlen, D.; Miller, E.R. 3rd. Differences in vitamin $\mathrm{D}$ status as a possible contributor to the racial disparity in peripheral arterial disease. Am. J. Clin. Nutr., 2008, 88(6), 1569-1577. 
[75] Park, C.W.; Oh, Y.S.; Shin, Y.S.; Kim, C.M.; Kim, Y.S.; Kim, S.Y.; Choi, E.J.; Chang Y.S.; Bang, B.K. Intravenous calcitriol regresses myocardial hypertrophy in hemodialysis patients with secondary hyperparathyroidism. Am. J. Kidney Dis., 1999, 33(1), 7381.

[76] Kim, H.W.; Park, C.W.; Shin, Y.S.; Kim, Y.S.; Shin, S.J.; Choi, E.J.; Chang, Y.S.; Bang, B.K. Calcitriol regresses cardiac hypertrophy and QT dispersion in secondary hyperparathyroidism on hemodialysis. Nephron Clin. Pract., 2006, 102(1), c21-29.

[77] Scragg, R.; Jackson, R.; Holdaway, I.M.; Lim, T.; Beaglehole, R. Myocardial infarction is inversely associated with plasma 25hydroxyvitamin D3 levels: a community-based study. Int. J. Epidemiol., 1990, 19, 559-563.

[78] Giovannucci, E.; Liu, Y.; Hollis, B.W.; Rimm, E.B. 25Hydroxyvitamin D and risk of myocardial infarction in men. Arch. Intern. Med., 2008, 168, 1174-1180.

[79] Rajasree, S.; Rajpal, K.; Kartha, C.C.; Sarma, P.S.; Kutty, V.R.; Iyer, C.S.; Girija, G. Serum 25-hydroxyvitamin D3 levels are elevated in South Indian patients with ischemic heart disease. Eur. J. Epidemiol., 2001, 17, 567-571.

[80] Poole, K.E.; Loveridge, N.; Barker, P.J.; Halsall, D.J.; Rose, C.; Reeve, J.; Warburton, E.A. Reduced vitamin D in acute stroke. Stroke, 2006, 37(1), 243-245.

[81] Pilz, S.; Dobnig, H.; Fischer, J.E.; Wellnitz, B.; Seelhorst, U.; Boehm, B.O.; Marz, W. Low vitamin D levels predict stroke in patients referred to coronary angiography. Stroke, 2008, 39, 26112613.

[82] Mancuso, P.; Rahman, A.; Hershey, S.D.; Dandu, L.; Nibbelink, K.A.; Simpson, R.U. 1,25-dihydroxyvitamin-D3 treatment reduces cardiac hypertrophy and left ventricular diameter in spontaneously hypertensive heart failure-prone $(\mathrm{cp} /+)$ rats independent of changes in serum leptin. J. Cardiovasc. Pharmacol., 2008, 51(6), 559-564.

[83] Simpson, R.U.; Hershey, S.H.; Nibbelink, K.A. Characterization of heart size and blood pressure in the vitamin D receptor knockout mouse. J. Steroid Biochem. Mol. Biol., 2007, 103(3-5), 521-524.

[84] Rhaman, A.; Hershey, S.; Ahmed, S.; Nibbelink, K.; Simpson, R.U. Heart extracellular matrix gene expression profile in the vitamin D receptor knock-out mice. J. Steroid Biochem. Mol. Biol., 2007, 103(3-5), 416-419.

[85] Pilz, S.; Marz, W.; Wellnitz, B.; Seelhorst, U.; Fahrleitner-Pammer, A.; Dimai, H.P.; Boehm, B.O.; Dobnig, H. Association of vitamin $\mathrm{D}$ deficiency with heart failure and sudden cardiac death in a large cross-sectional study of patients referred for coronary angiography. J. Clin. Endocrinol. Metab., 2008, 93(10), 3927-3935.

[86] Zittermann, A.; Schleithoff, S.S.; Gotting, C.; Dronow, O.; Fuchs, U.; Kuhn, J.; Kleesiek, K.; Tenderich, G.; Koerfer, R. Poor outcome in end-stage heart failure patients with low circulating calcitriol levels. Eur. J. Heart Fail., 2008, 10(3), 321-327.

[87] Zittermann, A.; Fischer, J.; Schleithoff, S.S.; Tenderich, G.; Fuchs, U.; Koerfer, R. Patients with congestive heart failure and healthy controls differ in vitamin D-associated lifestyle factors. Int. J. Vitam. Nutr. Res., 2007, 77(4), 280-288.

[88] Wang, T.J.; Pencina, M.J.; Booth, S.L.; Jacques, P.F.; Ingelsson, E.; Lanier, K.; Benjamin, E.J.; D'Agostino, R.B.; Wolf, M.; Vasan, R.S. Vitamin D deficiency and risk of cardiovascular disease. Circulation, 2008, 117, 503-511.

[89] Ginde, A.A.; Scragg, R.; Schwartz, R.S.; Camargo, C.A. Jr. Prospective study of serum 25-hydroxyvitamin D level, cardiovascular disease mortality, and all-cause mortality in older U.S. adults. $J$. Am. Geriatr. Soc., 2009, 57(9), 1595-1603.

[90] Pilz, S.; Dobnig, H.; Nijpels, G.; Heine, R.J.; Stehouwer, C.D.; Snijder, M.B.; van Dam R.M.; Dekker, J.M. Vitamin D and mortality in older men and women. Clin. Endocrinol., 2009, 71(5), 666672 .

[91] Dobnig, H.; Pilz, S.; Scharnagl, H.; Renner, W.; Seelhorst, U.; Wellnitz, B.; Kinkeldei J.; Boehm, B.O.; Weihrauch, G.; Maerz, W. Independent association of low serum 25-hydroxyvitamin D and 1,25 dihydroxyvitamin D levels with all-cause and cardiovascular mortality. Arch. Intern. Med., 2008, 168, 1340-1349.

[92] Kunitomo, M.; Kinoshita, K.; Bando, Y. Experimental atherosclerosis in rats fed a vitamin $\mathrm{D}$, cholesterol-rich diet. J. Pharmacobiodyn., 1981, 4, 718-723.

[93] Ito, M.; Cho, B.H.; Kummerow, F.A. Effects of a dietary magnesium deficiency and excess vitamin D3 on swine coronary arteries. J. Am. Coll. Nut., 1990, 9, 155-163.

[94] Hsia, J.; Heiss, G.; Ren, H.; Allison, M.; Dolan, N.C.; Greenland, P.; Heckbert, S.R.; Johnson, K.C.; Manson, J.E.; Sidney, S.; Trevisan, M.; Women's Health Initiative Investigators. Calcium/vitamin D supplementation and cardiovascular events. Circulation, 2007, 115, 827-828.

[95] Michos, E.D.; Blumenthal, R.S. Vitamin D supplementation and cardiovascular disease risk. Circulation, 2007, 115, 827-828.

[96] Bolland, M.J.; Barber, P.A.; Dought, R.N.; Mason, B.; Horne, A.; Ames, R.; Gamble. G.D.; Grey, A.; Reid, I.R. Vascular events in healthy older women receiving calcium supplementation: randomized controlled trial. BMJ, 2008, 336(7638), 262-266.

[97] Autier, P.; Gandini, S. Vitamin D supplementation and total mortality: a meta-analysis of randomized controlled trials. Arch. Intern. Med., 2007, 167(16), 1730-1737.

[98] Boxer, R.S.; Dauser, D.A.; Walsh, S.J.; Hager, W.D.; Kenny, A.M. The association between vitamin $\mathrm{D}$ and inflammation with the 6minute walk and frailty in patients with heart failure. J. Am. Geriatr. Soc., 2008, 56(3), 454-461.

[99] Brigham and Women's Hospital: Largest study of vitamin D and omega-3s set to begin soon at Brigham and Women's hospital. Retrieved August 25, 2009, from http://www.brighamandwomens.org/ Pressreleases/PressRelease.aspx ?PageID $=508$

(C) Michos et al.; Licensee Bentham Open.

This is an open access article licensed under the terms of the Creative Commons Attribution Non-Commercial License (http://creativecommons.org/licenses/ by-nc/3.0/) which permits unrestricted, non-commercial use, distribution and reproduction in any medium, provided the work is properly cited. 